\title{
EREBEA
}

Revista de Humanidades y Ciencias Sociales

Núm. 9 (2019), pp. 133-160

ISSN: 0214-0691

http://dx.doi.org/10.33776/erebea.v9i0.3852

\section{LAS HUERTAS DE MURCIA Y ORIHUELA, LA HOMOGENEIDAD DE UN PAISAJE DEL AGUA CON DOS REALIDADES DIFERENTES}

\author{
Gregorio Canales Martínez \\ Universidad de Alicante \\ María Dolores Ponce Sánchez \\ Universidad de Murcia
}

RESUMEN

El presente estudio analiza los regadíos históricos, Huertas de Murcia y Orihuela, como paradigmático paisaje del agua que sigue vigente desde el siglo IX. La creación antrópica de una precisa y jerárquica malla de canalizaciones riego-avenamiento, en los terrenos marjalencos originales, permitió reutilizar las filtraciones de las tierras regadas para volver a irrigar o abocarlas nuevamente al río, esta práctica creó un regadío eficaz, sostenible y de rasgos similares. Sin embargo, en la actualidad, diversos factores socioeconómicos y culturales, iniciados a finales del pasado siglo y todavía amenazantes, han conducido a su regresión. Una pérdida que se ha concretado en un vertiginoso proceso de distinta naturaleza, debido al crecimiento urbano-periurbano de la capital murciana y al uso turísticoresidencial de la vega oriolana por su proximidad a la costa.

Palabras Clave

Huerta; riego; avenamiento; patrimonio; urbanización.

Fecha de recepción: 27 de noviembre de 2019 Fecha de aceptación: 5 de diciembre de 2019
Abstract

This paper analyses the historic irrigations of Murcia's and Orihuela's Huertas as paradigmatic water landscape in use since the 9th Century. The anthropic creation of a precise and hierarchical irrigation-drainage net in the original swampy terrain allowed to reuse the filtrations of irrigated lands to water again or decant into the river. This practice created an efficient irrigation mode, sustainable and similar in features. However, at this moment, diverse socioeconomic and cultural factors, initiated in the last period of the past century and sill threatening, have caused its regression. A loss, which has led to a vertiginous process of different nature due to the urban and suburban growth of the murcian capital and the touristic-residential use of the orihuela's plain for its proximity to the coast.

\section{KeYwORDS}

Orchard; irrigation; drainage; heritage; urbanization. 



\section{INTRODUCCIÓN.}

La llanura aluvial del río Segura, objeto de análisis, se caracteriza por ser un espacio agrícola de regadío intensivo, perteneciente al arco mediterráneo español y enmarcado como uno de los seis paisajes europeos de Huerta identificados por el informe Dobris. Este documento de la Agencia Europea de Medioambiente proporciona un primer dato de su consideración como paisaje único y la condición de dispersión en lugares puntuales del arco mediterráneo (EEA, 1997). Adicionalmente, ambas vegas se reconocen como un agrosistema que caracteriza, define el territorio y la cultura en las áreas en las que se ha desarrollado, tal como determina el Convenio Europeo del Paisaje, que contempla la calidad y diversidad de éstas como recurso que incide en la identidad y bienestar de la población local. Lo que hace necesario fijar un planteamiento integral de la zona que preserve la idiosincrasia inherente al lugar (Antrop, 2005) de manera sostenible en el marco de un desarrollo económico global.

Este secular espacio regado conforma una región natural cuyas características que no han pasado desapercibidas para los estudiosos de esta realidad, que ensalzaron el fértil llano donde "la preciosa vega de las huertas de Murcia y Orihuela... unidas, forman el valle más hermoso y ameno de cuantos se conocen" (Roca de Togores, 1832). La disgregación de este territorio quedó ordenada por la Sentencia Arbitral de Torrellas de 1304 y el posterior acuerdo de Elche, rubricado al año siguiente, por él la demarcación oriolana se incorporó al Reino de Valencia, al segregarse del recién creado reino murciano. Este hecho ha sido calificado de "absurda amputación" (Gil Olcina, 1976) al romper la unidad de cuenca, lo que ha generado enfrenamientos entre las dos áreas regadas hasta nuestros días. En la separación de este enclave agrario de producción intensiva, por parte de ambas coronas, debió pesar el interés por garantizar la subsistencia, al disponer de unos recursos de vital importancia como eran las cosechas de cereales, claves en la dieta alimenticia. Sin olvidar además, que la continuidad de los condicionantes físicos de la planicie se corresponden asimismo con una marcada dependencia de carácter hidráulico, pues la otrora Huerta de Orihuela, hoy Vega Baja del Segura, recibe los avenamientos y las aguas sobrantes del regadío vecino, que, por estar emplazado a una mayor cota encuentra a través de ella su salida hacia el Segura, a la vez que suministra riego a sus predios. 
I. LA CONFIGURACIÓN HOMOGÉNEA DE UN PAISAJE ÚNICO

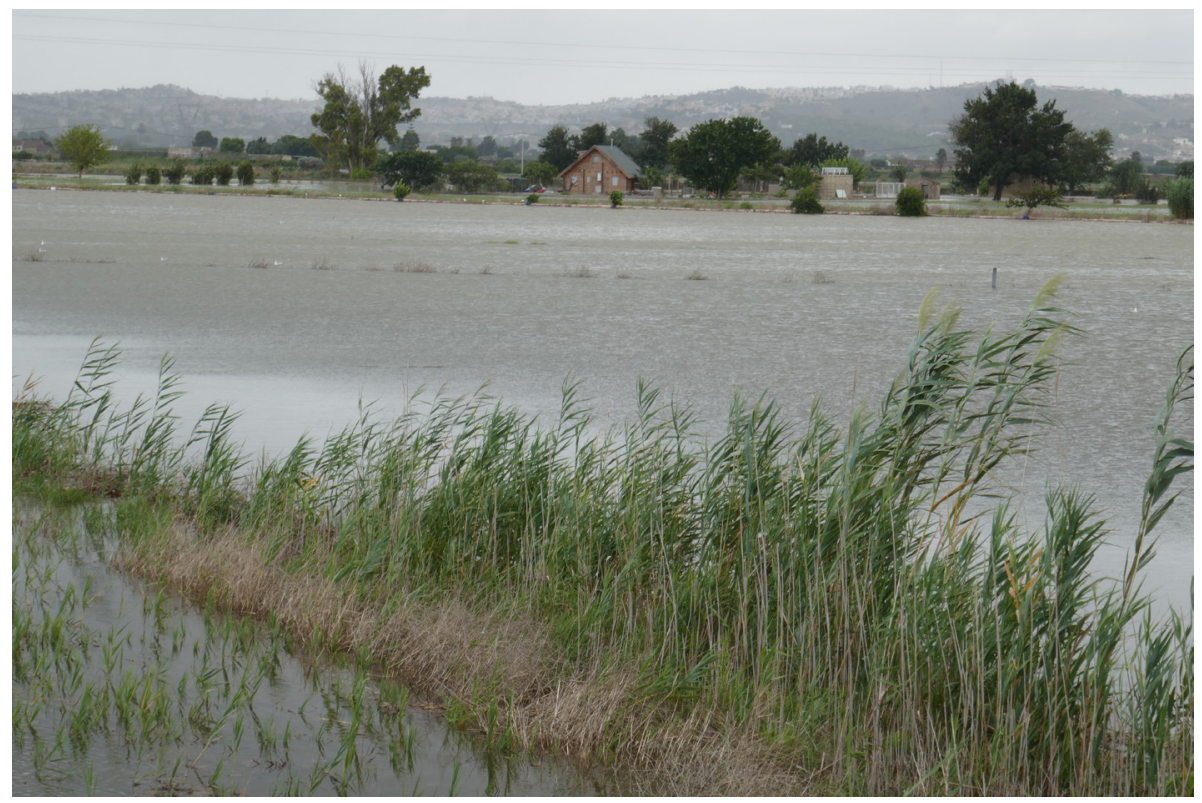

Fig. 1. La inundación de septiembre de 2019 puso de manifiesto que la creación de la Huerta transformó un antiguo espacio alagado (Fotografía G. Canales).

Murcia y Orihuela lideraron el proceso de ocupación y aprovechamiento de un llano aluvial provisto de extraordinarias posibilidades para el asentamiento humano, proporcionadas por el río Segura y la red de emisarios de su cuenca fluvial. El principal colector se caracterizaba históricamente por su naturaleza disonante, en tanto que adolecía de un marcado estiaje, frente a grandes crecidas provocadas por episodios pluviométricos de marcada irregularidad y eventualidad, capaces de anegar toda la planicie. Esta condición, le adjudica de nuevo dos impactos marcadamente opuestos; por una parte, aporta limos dando a los terrenos un atributo muy apreciado -la fertilidad-; por otra, le atribuye una peculiaridad muy temida, la devastación que originan las avenidas. Las mencionadas ciudades dejan advertir en la elección de sus emplazamientos, el conocimiento de esta secuencia de riesgo-beneficio y viceversa.

La primera, mediante un asentamiento ex novo en el fondo del valle, donde, la interpretación de textos árabes y castellanos, junto a algunos testimonios arqueológicos, permiten constatar la transformación de un paisaje natural a otro humanizado por la sociedad islámica (Martínez, 2017); mientras que la segunda, optó en sus inicios por ocupar una cota por encina del lecho en el Cabezo de San Miguel, unido a la Sierra de Orihuela $(634 \mathrm{~m})$, donde se data un yacimiento del Bronce Final (Diz, 2017) con continuidad hasta época tardorromana, momento 
en que aparece como enclave militar fortificado en la firma del Pacto de Teodomiro en abril del ańo 713. El aumento demográfico del siglo IX propició que se ocupara la margen izquierda del río donde la vulnerabilidad era mayor, pero a cambio la disponibilidad de agua corriente facilitaba el abastecimiento, toda vez que se había iniciado el proceso de irrigación en la planicie aluvial (Franco, 2017). En dicha centuria se asiste asimismo a la fundación de Murcia por Abderramán II en el 825 (Madinat Mursiya), sobre terrenos de almarjales que requerían ser desecados para alcanzar un doble objetivo. Uno de los propósitos, respondía a las necesidades del Estado omeya, pues precisaba el establecimiento del hecho urbano como herramienta de control territorial, para hacer frente a las continuas revueltas frecuentes en la periferia del emirato. El otro, fue conseguir el desarrollo agrario, tras la creación del sistema de riego en terrenos mal drenados y sometidos a un peligro continuo por un régimen de avenidas devastadoras (Jiménez, 2014).

De estos dos centros de población, los grupos humanos identifican los signos y valores territoriales de la llanura de crecida y descubren las potencialidades que los suelos predominantes pueden aportar para la supervivencia-aguas someras, lodazales y tierras limosas, aunque salinas (secuencia que sustenta la conversión al paisaje Huerta)- si bien, aceptando un espacio de peligrosidad que queda suficientemente compensado por las ventajas de la puesta en cultivo. Estos atributos definitorios rigen las actuaciones de sus habitantes, que llevan a cabo un marcado proceso de antropización, entendido éste como la acción desempeñada por los habitantes sobre el medio ambiente para convertirlo en su aliado sin hacerle perder sus cualidades esenciales. Así se construyó la Huerta como paradigma de los paisajes del agua, el Segura se convierte en el auténtico artífice y ella representa su composición más sublime, nacida en las márgenes del curso fluvial. El río constituye el modelador espacial y, por ende, el causante de una auténtica cultura que durante milenios ha mantenido el desarrollo socioeconómico de este territorio en sus orígenes marítimo.

Es conveniente recordar el histórico marco geológico donde surge este agrosistema, un antiguo golfo cegado por el aluvionamiento de los ríos Guadalentín-Segura en la parte más occidental, que constituye la Huerta de Murcia. Investigaciones recientes han señalado que hacia el año 3.000 a. C la línea de costa se situaría en la actual localización de la ciudad de Orihuela, a partir de esta fecha, al intenso proceso de sedimentación se le suma el río Vinalopó, que, junto a un progresivo levantamiento de la plataforma continental, todavía activo, provocaría la colmatación del sector oriental, el denominado Sinus Ilicitanus. A comienzos de la presente era ya mostraba muy poca profundidad y hacia el año 500 d. C la desembocadura del Segura ya terminaba en Guardamar (TentManclús y Soria, 2014), dando lugar a la antigua Huerta de Orihuela.

La génesis de este paisaje emerge en la llanura de crecida de este colector, enclave que constituye un magnífico ejemplo de las difíciles relaciones establecidas entre el medio físico y la acción humana, pues fue la intervención de esta última 


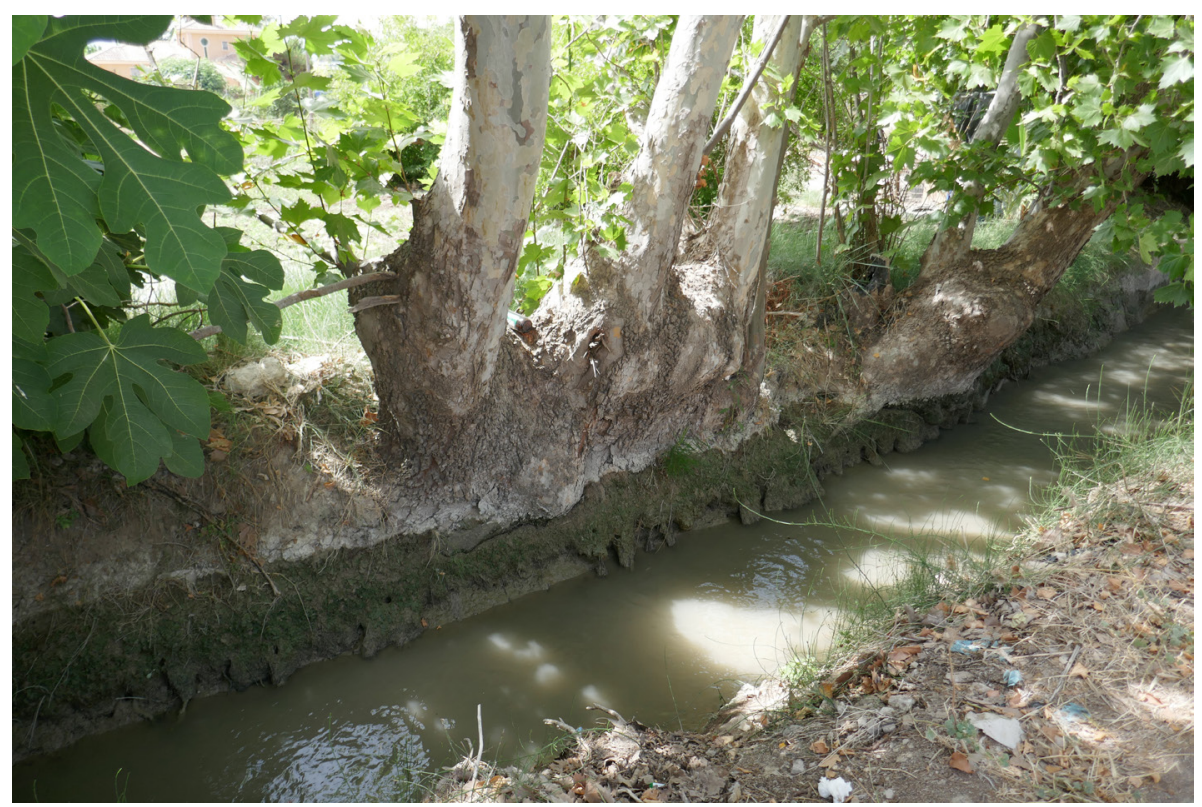

Fig. 2. La Huerta todavía conserva cauces excavados en tierra con quijeros reforzados por plantaciones arbóreas como en el medievo (Fotografía G. Canales).

la que transforma el espacio en la actual llanura de inundación (Lillo, 2000). La profunda transformación empezó a gestarse hace más de un milenio, a partir de la expresa voluntad de los grupos sociales asentados en sus inmediaciones, de plantear mediante la agricultura una nueva relación con el ecosistema natural y fijar en él la morada. Para entender esta dinámica es necesario aludir a la morfología del Segura, se trata en origen, de un cauce sobreelevado producto de su hidrodinámica. Así, en los tramos de perfil longitudinal débil surgen barras de acumulación de gran sinuosidad a ambas márgenes, a modo de diques naturales, denominados motas, que impiden a las escorrentías de las laderas del valle reintegrarse al curso fluvial.

El comportamiento del río ha sido estudiado con precisión por Lillo Carpio, quien señala que, en función del gradiente, caudal y carga transportada, conforma una planicie de marcada horizontalidad, ausente de terrazas, donde el discurrir hace que se inserte en sus propios aluviones. Esta geomorfología remarca la complejidad de la cuenca, por un lado, produce en el llano múltiples corrientes migratorias de carácter espontáneo, producto de la circulación derivada; por otro, impide el retorno de esas aguas al lecho principal, que discurren paralelas a él hasta encontrar un punto de confluencia, o de lo contrario, configuran almarjales. Las motas y los surcos alternantes son los dos elementos esenciales para comprender la creación del paisaje huertano, por cuanto las primeras se erigen como las vías de 
tránsito principales, mientras que los segundos serán aprovechados para diseñar la red de riego.

La intervención antrópica convirtió un patrón de dinámica natural en otro de carácter artificial, que aumentó su envergadura y extensión, al vislumbrar las potencialidades y oportunidades que ofrecía el territorio una vez desecado en su totalidad. Además, supo volver a reproducir este mismo prototipo en cada una de las sucesivas ampliaciones hasta llegar a cubrir toda la planicie, configurando subsistemas que siguen en esencia un comportamiento similar al general; por cuanto todas estas canalizaciones se encuentran también flanqueadas por motas, pero en este caso, fruto de las acciones de limpieza o mondas realizadas por los agricultores y que, al quedar sobreelevadas, componen una vez más los ejes de comunicación y localización del poblamiento. De esta manera tan elemental fue como se afrontó el peligro de inundación por desbordamiento del río, con actitudes de defensa para preservar el espacio vital amenazado a partir de imitar el funcionamiento de la naturaleza.

\section{El Regadío huertano, UN GRAN EDIFICIO HIDRÁUlico}

El regadío intensivo implantado desde época andalusí, en ambas márgenes del río Segura, adquiere mayor trascendencia si se tiene en cuenta que se desarrolló en un territorio de clima subárido con escasos recursos hídricos. Hay que destacar que el comportamiento del curso fluvial, como describen las crónicas árabes de los siglos X y XI, se identificó de inmediato como similar al del Nilo por sus avenidas y aportaciones de limos. Este hecho ya quedó recogido por Al-Razi quien señala que en la Cora de Tudmir "toda su tierra riega el río, assi como fase el rio de Nilo en la tierra de provisión"; igualmente, Al-Udri subraya que "Su tierra está regada por un rio de iguales propiedades que el Nilo de Egipto". El aprovechamiento de las crecidas fue una situación ya controlada y dirigida por los egipcios, familias yundíes llegadas con el ejército de Baly b. Bisr que se asentaron aquí a mediados del siglo VIII, como especifica el último autor "se estableció en ella el yund de Egipto (año 743)" (Gea, 1995). En el transcurso de este espacio temporal se produjo el inicio del proceso de saneamiento y colonización del llano objeto de estudio. La acción transformadora comenzó a partir de la construcción de un complejo hidráulico, cuyo elemento fundamental son los azudes vinculados a la red de riego.

El geógrafo andalusí Al-Udri dejó constancia del espacio regado en su escrito donde aporta un relato vivo y palpitante de lo que fue la región a finales del califato, cuando relata "El territorio de Tudmir es famoso por la fecundidad de sus tierras y la exquisitez de sus frutos", la feracidad de esta tierra está en estrecha relación con su río y alude a las infraestructuras hidráulicas que parten de él (Molina López, 1972). Este proceso desencadenó una serie de ventajas que redundaron en la población, pues se garantizó y mejoró la subsistencia alimenticia 


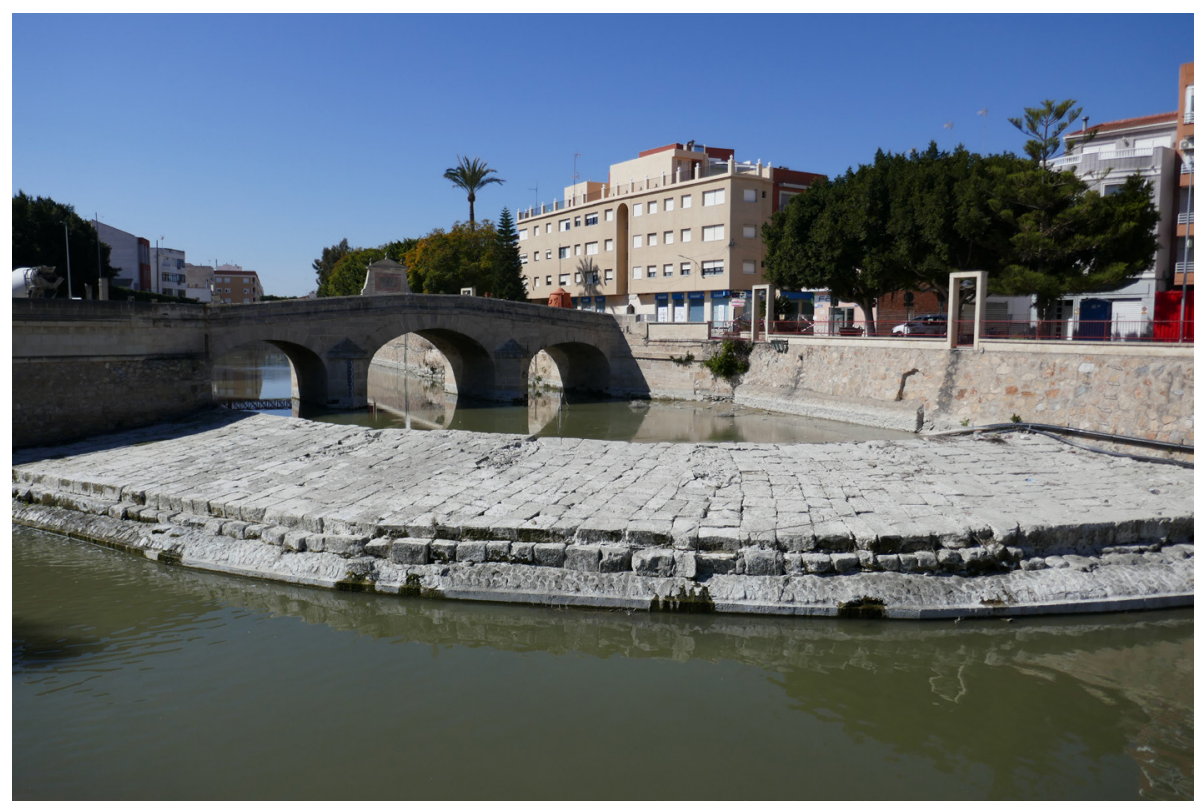

Fig. 3. Azud de Rojales (siglo XVII), modelo representativo de las presas de derivación que dan origen a la red de riego (Fotografía G. Canales).

frente a los anteriores aprovechamientos, entre los que destaca la caza, la pesca y la recolección silvestre; sin olvidar el avance sanitario que supuso reducir el paludismo, mal endémico en la zona, con lo que incrementó el vecindario y posibilitó un hábitat sostenible. La extraordinaria transformación de un espacio pantanoso fue posible a las sucesivas ampliaciones del sistema hidráulico, en una dilatada relación espacio-tiempo, siguiendo el patrón desarrollado por los árabes.

La red de riego de la Huerta requiere la existencia de una zona de captación en el lecho del río, que es el azud; a continuación, exige implantar la malla de distribución de caudales para dirigirlos por el territorio agrícola, una amplia retícula denominada "aguas vivas"; igualmente, se precisa toda una trama inversa a la anterior para la recogida de avenamientos, conocida como "aguas muertas". La organización del regadío supuso un gran esfuerzo y pone de manifiesto el conocimiento minucioso que la población tenía del territorio, ya que había que superar los inconvenientes que imponía la exigua pendiente, para el reparto de los recursos hídricos por gravedad, y el horizonte impermeable de arcillas en el subsuelo que favorecía el encharcamiento.

Las Ordenanzas de la Huerta de Murcia determinan hasta cuatro tipos de acueductos, proyectados en jerarquía para cubrir las necesidades de abastecimiento. La relación arranca de las mencionadas acequias mayores, que sangran el río y se ramifican en las acequias menores, de donde toman los brazales, 
y éstos suministran a las regaderas, las que conducen el agua a las parcelas, aunque hay que destacar que cada conducción dota directamente sus tierras linderas. El mismo modelo reproduce la Huerta de Orihuela, si bien en ésta algunos cauces cambian de nombre, así, las acequias menores se llaman también arrobas, los brazales se conocen en algunas poblaciones como hilas y las derivaciones de ellos como hijuelas.

La red de avenamiento presenta una estructura similar e inversa a la anterior, para reunir los drenajes producidos por la percolación tras el riego. El cometido y nombre de estas categorías se detalla en la normativa murciana de la siguiente manera: "Los cauces de aguas muertas sirven para recibir los avenamientos o escurrimbres de las tierras, descargándolas de la excesiva humedad que les perjudica. Estos son los escorredores, las azarbetas y los azarbes o landronas. Los escorredores reciben los avenamientos de uno o de dos herederos; las azarbetas los de tres o más herederos y los azarbes o landronas son los cauces en que se reúnen dos o más azarbetas. También suele llamarse meranchos o meranchones" (artículo 7, Capítulo II, Ordenanzas de la Huerta de Murcia, 2008). El regadío oriolano contiguo, al disponer de menor cota altimétrica requiere una mayor densidad de canalizaciones de recogida.

La envergadura de esta infraestructura queda fijada con total nitidez en los estatutos de los distintos juzgados, comunidades o sindicatos de riego que provienen de esta demarcación, cuya finalidad es "recibir las espurgaciones, amarguras, salobres y desagües de riego procedentes de las tierras de labor". La jerarquía de dicha trama se inicia igualmente en los escorredores, que avenan a las azarbetas y éstas, a su vez, lo hacen a los azarbes menores que abocan a los azarbes mayores, los que vierten "sus aguas en el río o en otros cauces de la misma naturaleza, o de aguas vivas" (artículo 16, Título Preliminar, Ordenanzas del Juzgado Privativo de Aguas de Orihuela y Pueblos de su Marco, 2014), iniciándose así de nuevo el proceso de reparto de caudales ya descrito.

Este sistema es esencial en una cuenca deficitaria como la del Segura, pues gracias a ella se reutilizan los caudales filtrados tras los riegos, ya que la escasez de recursos hídricos originó que en las sucesivas ampliaciones del regadío se usaran estas aguas denominadas muertas, a las que se han atribuido otros vocablos como el de retorno (Canales y Ponce, 2019), o más recientemente, el profesor Gil Olcina (2019) las califica de resucitadas, en tanto que su condición de ya usadas no las exime de recuperar la función de vivas y volver a irrigar. De esta forma, en la agrarización del valle se consiguió un uso eficiente, todavía vigente, al obtener el máximo rendimiento de los exiguos recursos disponibles a partir de un circuito cerrado de canalizaciones que extrae las aguas del río y las retorna de nuevo a él. La recogida de las aguas de drenaje y su uso para el riego cobra mayor envergadura conforme la red hidráulica se aproxima al mar, en virtud del exiguo desnivel.

El desarrollo de todo este conjunto arquitectónico, según las peculiaridades señaladas, obligó a realizar conducciones encabalgadas, lo que los huertanos 


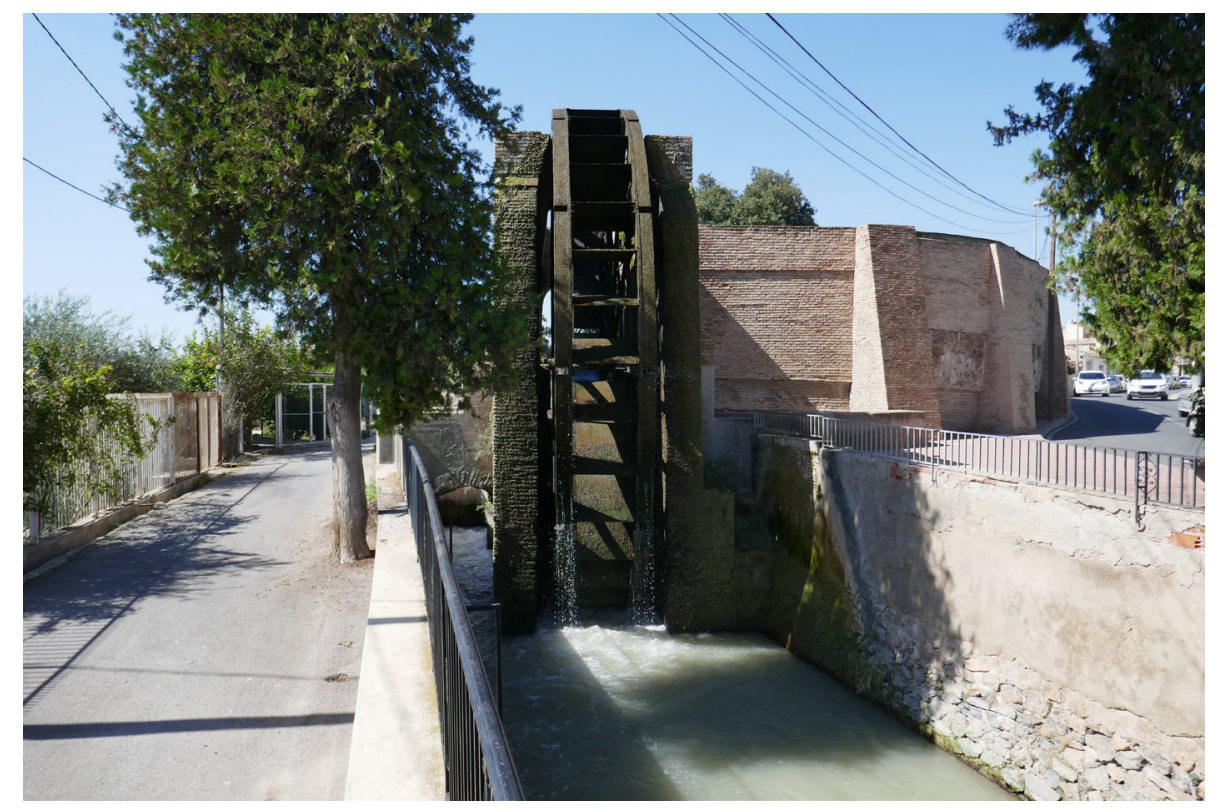

Fig. 4. La Rueda de la Ñora, emplazada en la Acequia de Aljufía, y su acueducto del siglo XV forman uno de los monumentos más representativos de la Huerta de Murcia (Fotografía G. Canales).

denominan "cabalgadores en la red". Es precisamente este elemento constructivo, $\tan$ notorio en esa estructura ingenieril, el que le otorga a la Huerta, en mayor medida, la consideración de arquitectura del agua. Una retícula superpuesta muy presente en casi todos los heredamientos de regantes, desde sus inicios en la Contraparada hasta la numerosa retícula de evacuación que confluye en el río Segura a escasos metros de su desembocadura. En el laberinto de canales los diversos tipos de superposiciones son exponente de la maestría y conocimiento en el arte del uso y gestión de los recursos hídricos; las mencionadas estructuras, bien sean subterráneas o aéreas, fueron posibles por la utilización de tubos metálicos o muros de sillería, unidos por lo general mediante mampostería ordinaria.

Para una mayor comprensión y ponderación de la monumental obra hidráulica que se da en el territorio, conviene precisar que hasta 1793 el tejido que conforma la densa malla de acueductos se denominaba edificio por los agricultores, término que fue prohibido por el Tribunal de Castilla al no ser comprensible fuera de este ámbito (Azud de Alfeitamí, 1793); si bien, en la actualidad subsiste su uso entre las personas de mayor edad e incluso se mantiene de forma testimonial en las Ordenanzas de la Huerta de Murcia que, tras la revisión y adaptación en 2008 de las precedentes en 1849 , todavía mantiene el vocablo edificio que aplica a los conductos "a que van destinadas las aguas", considerando como parte integrante 
de ellos: "el agua, el cauce, los quijeros (cajeros), y las márgenes" tanto de aguas vivas como muertas.

La grandiosa construcción que estructura el paisaje se acopló con perfecto acierto para la transformación del medio, cuyo resultado es visible sobre todo en los azudes y en los cruces a distinto nivel de sus cauces, a la vez que resulta imperceptible en la cuenca visual del observador cuando los canales se encuentran construidos en tierra y no se alzan sobre la superficie. El desarrollo de esta ingeniería civil supuso la puesta en cultivo de una superficie de 30.871 hectáreas (De Mancha, 1836 y Roca de Togores, 1832) repartidas de forma desigual entre ambas vegas (un $34 \%$ para Murcia y el $66 \%$ para Orihuela), una vez culminado el proceso de colonización en una planicie aluvial de escasa pendiente, inferior al 0,5 por mil; incluso se registran ínfimos valores para alguno de sus ramales de riego-avenamiento, al mostrar recorridos por debajo del 0,1 por mil.

\section{LA EFICIENTE Y PRECISA OBRA HIDRÁULICA}

El sistema de riego de sendas Huertas se ha caracterizado por la máxima eficiencia en el uso y distribución de los caudales, funciones desempeñadas secularmente por los órganos de gestión competentes en cada una de ellas, la Junta de Hacendados, para la de Murcia y el Juzgado Privativo de Aguas para la de Orihuela. La finalidad en ambos casos ha sido, no sólo, obtener la mayor rentabilidad ante los escasos recursos hídricos disponibles, sino también, propiciar el consenso entre los heredamientos en los repartos de agua, evitar conflictos y establecer reglas de funcionamiento, que quedan recogidas en sus respectivas ordenanzas. La máxima expresión de esta organización se puede comprobar en los turnos de suministro de volúmenes, los entandamientos, que se establecen para los distintos cauces. Estas normas, de transmisión oral en origen pues provienen del derecho consuetudinario, con el tiempo se plasmaron por escrito en los respectivos reglamentos internos, en virtud de la propia ampliación y evolución del espacio regado, en aras de facilitar la convivencia entre los usuarios.

Los acueductos se subdividen en secciones o tramos de desigual longitud, que se acotan por las denominadas paradas, donde en ellas se emplazan los partidores o boqueras para permitir o cancelar el paso de las aguas, conocidas popularmente como "Paradas de ataje". En estas construcciones se ubican los tablachos, antaño de madera, hoy compuertas por lo general metálicas, para obstaculizar el fluir de la corriente, cuya función consiste en elevar su nivel y poder así derivarlo hacia las tierras de labor; mecanismo que igualmente se emplaza en los laterales de las canalizaciones, donde se ubican las tomas de derivación correspondientes (brazales o ventanas). El entande determina la secuencia de abastecimiento y el tiempo correspondiente a las distintas divisiones que, según los casos, oscila desde una hora, e incluso menos, hasta las veinticuatro o más. Este procedimiento se repite, según la canalización, de forma pautada cada mes con períodos variables 
en el número de días. La descripción que se ha presentado puede parecer a priori un modelo de regulación sencillo y estandarizado, que lo es, sin embargo, en el ingenioso sistema de turnos rigen otros patrones propios de algunas conducciones que constatan la complejidad de este regadío.

Respecto a estas peculiaridades se pueden citar, la existencia de tomas abiertas en la red secundaria, que se abastece de caudales siempre que circule el agua por el canal principal; los arbellones, son los boquetes que sen dan en la solera de una acequia, suele coincidir cuando se produce el encabalgamiento de un cauce sobre otro al que suministra agua durante su período de tanda y actúa por consiguiente como toma abierta; los corribles, o el derecho a dotación extraordinaria que tienen algunas paradas, al cesar durante un día la tanda general y continuar el flujo por la red sin sometimiento a turno y sin que se puedan accionar los tablachos para interrumpir su curso; y, por último, las aguas de subida, aquellas que cuando finaliza el entande están asignadas en intervalos horarios, sólo a ciertos partidores, una vez acabado el tiempo establecido se inicia de nuevo el ciclo de riego desde la cabeza. Se trata en muchos casos de prácticas de origen desconocido pero trasmitidas entre generaciones y avaladas en los estatutos vigentes. Así, en las Ordenanzas del Juzgado Privativo de Aguas de Orihuela de 2014, que modifica las anteriores de 1836, se indica "quedan en su fuerza y vigor los entandes y repartos de agua que hay establecidos en la actualidad, ya sea por costumbre inmemorial, ya por concordias o convenios expresos, ya por acuerdos de común consentimientos de los herederos interesados" (art. $\left.{ }^{0} 129\right)$.

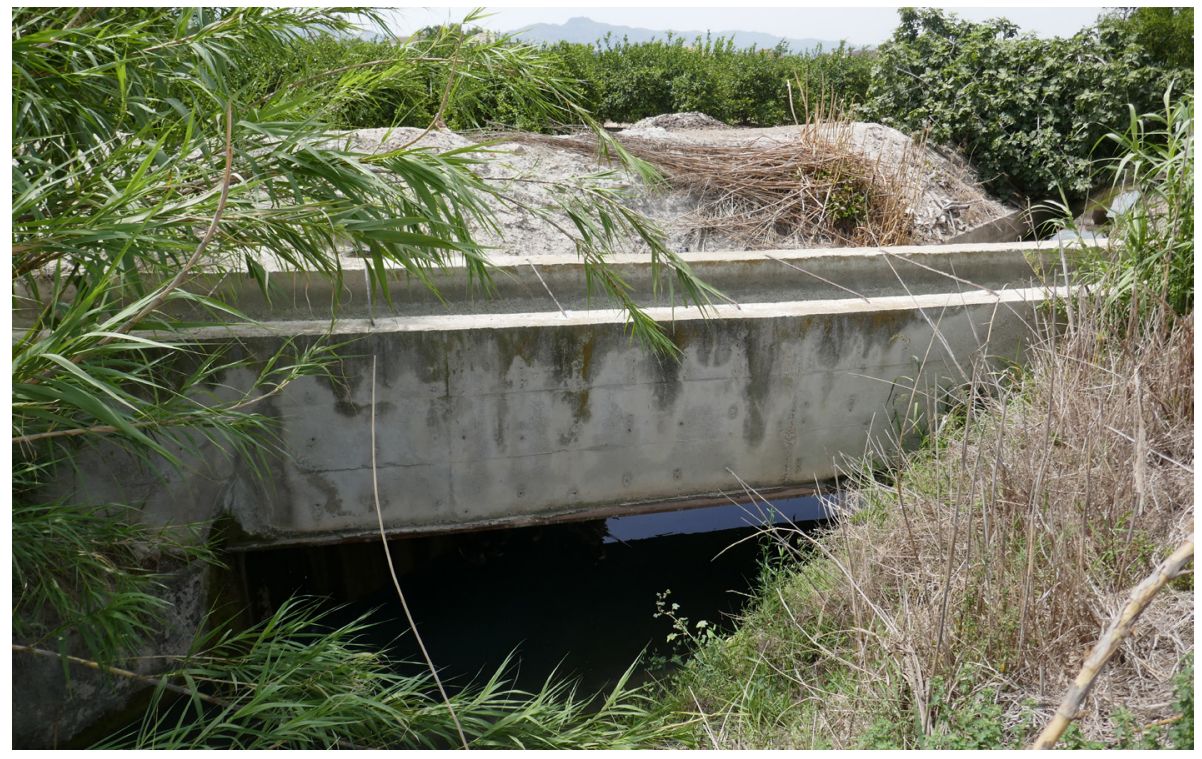

Fig. 5. Caja de la Acequia Nueva del Raal sobre el Merancho del Gil, obra que posibilitó ampliar el regadío en el siglo XVIII (Fotografía G. Canales). 
El trazado hidráulico que caracteriza este singular paisaje del agua ve alterada en parte su fisonomía debido al revestimiento, cimbrado y entubado de cauces, medida concebida para alcanzar un mejor aprovechamiento de este recurso, al evitar pérdidas por evaporación, filtraciones, y sobre todo, buscando un considerable ahorro económico en los gastos de mantenimiento y limpieza de las conducciones. Se trata de las mondas, estas labores suponían emplear en cada canalización a centenares de braceros que trabajaban a destajo durante varias jornadas, tradicionalmente en el mes de marzo. La realización de estas tareas todos los ańos y, en ocasiones, después de episodios de avenidas, se convertía en una necesidad insoslayable para la conservación de la estructura del regadío, y originaba la asunción de la Huerta como una obra comunitaria que beneficiaba a toda la población, por cuanto eliminaba el encharcamiento del suelo y los aspectos negativos que ello representaba para la salud pública.

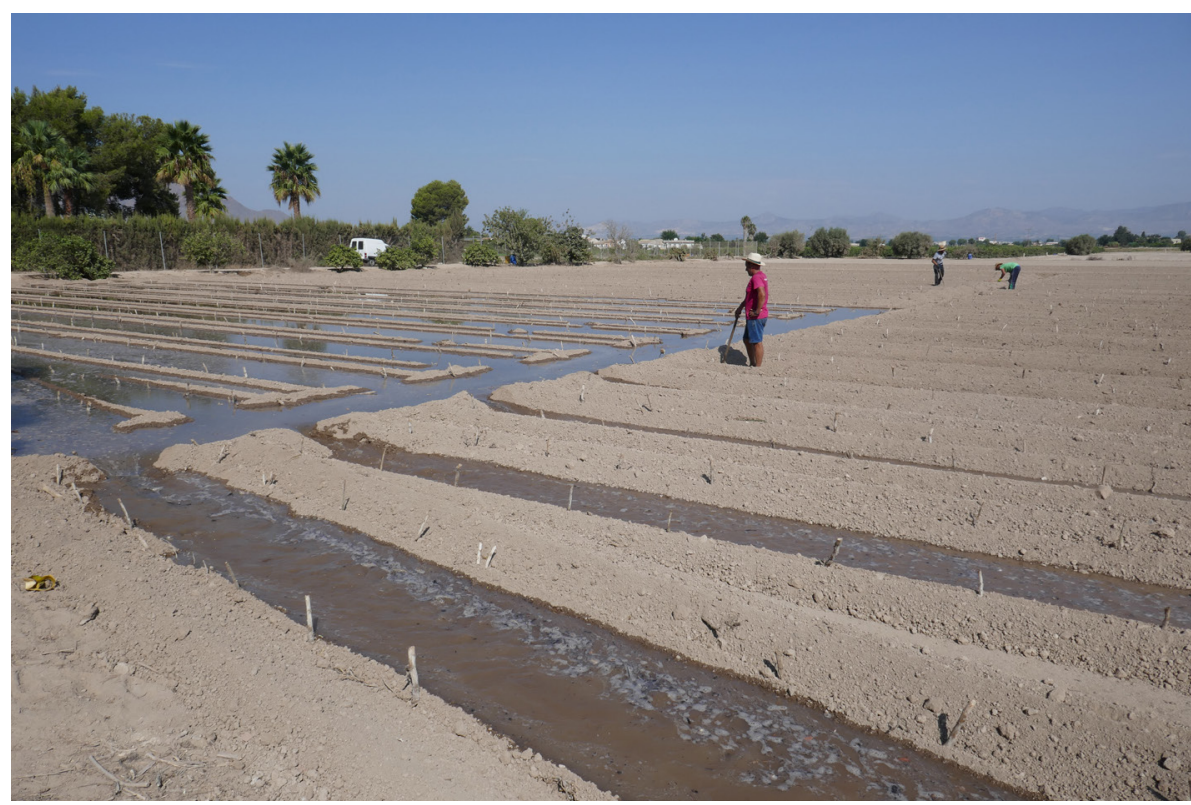

Fig. 6. El riego a manta predomina en el paisaje huertano y sus filtraciones, recogidas en la red de azarbes, se reutilizan de nuevo en el regadío (Fotografía G. Canales).

El cambio operado, que presenta en la actualidad casi la totalidad de las infraestructuras principales de riego-avenamiento, tuvo su aplicación a raíz de las inundaciones de los años setenta, cuando con el denominado Plan de Mejora para Comarcas Deprimidas, que encomendaba al IRYDA mediante la aplicación de la Ley de Reforma y Desarrollo Agrario (Decreto 118/1973 de 12 de enero) llevar a cabo empresas dirigidas a "un mejor aprovechamiento y conservación de los recursos naturales en aguas y tierras". En virtud de estas disposiciones se fue desnaturalizando 
la visión que se tenía de la Huerta, que pasó de zanjas excavadas en tierra y a cielo abierto, a otras tipologías constructivas, como fueron: las revestidas de cemento, donde todavía se puede observar la circulación del agua; las enlosadas, en las que se visualiza externamente su trazado, y, por último, las que discurren entubadas y sólo dejan en resalte aéreo los partidores o paradas. Esta sustitución supuso en muchos casos para los pequeños propietarios un gran endeudamiento, empresa que todavía no ha finalizado y, sin embargo, desde las administraciones competentes se insiste en una nueva actuación, el Plan de Modernización de Regadios, en el marco de los Programas de Desarrollo Rural 2014-20, que ahora tiene como finalidad la implantación del riego localizado frente al tradicional, por gravedad o a manta.

El regadío tradicional adolece de la mala imagen que contra él se ha venido trasmitiendo de forma generalizada, tanto en medios de comunicación como en distintos foros económicos, aduciendo que el riego por inundación es insostenible por el derroche que hace del recurso hídrico, aunque nunca se hace mención del nulo consumo de energía que requiere. Frente a él, alcanzan mayor aprobación las nuevas técnicas de riego con sistemas presurizados, a los que se atribuye un ahorro en el uso del agua, aunque acompañado de un incremento del gasto energético, con frecuencia poco considerado. A la sociedad no ha trascendido el alto valor que desde el ámbito científico se le da a la cultura creada en torno a este preciado bien, exponente de eficiencia en el uso de los principales recursos -agua y tierra- con su contribución a la función medioambiental como garante de la pervivencia de biodiversidad. Un sistema de verdadera arquitectura ácuea, exclusivo de la Huerta por el manto impermeable que hay en el subsuelo y que obligó a desarrollar la magnífica obra de ingeniería que caracteriza a sus conducciones de riego y avenamiento, a fin de que la colonización, y por ende el poblamiento, prosperara en toda la planicie aluvial. La desconexión entre los ámbitos de producción y consumo han tenido como contrapartida la falta de conocimiento sobre los valores del territorio, por una población con hábitos de comportamiento cada vez más urbanos, alejados de las prácticas y principios del medio rural, aunque éste sea su espacio identitario y circundante (Canales y Ponce, 2016).

\section{El Cambio de función de las aguas muertas a vivas}

La utilización reiterada de los retornos en la ampliación del regadío no ha sido reconocida en su verdadera trascendencia pues es un exponente de la gestión sostenible y eficiente que se logra con la escasa cantidad de agua disponible. Esta es la gran hazaña en la génesis de la Huerta, que incluso a partir de los sobrantes del río, cuando los hay, y, los que se recogen de la última red de avenamiento, es capaz de hacer posible la permanencia de uno de los humedales más importantes en el sur de la Comunidad Valenciana, El Parque Natural de El Hondo, a caballo entre el Bajo Segura y el Bajo Vinalopó. A la gran exigencia de caudales, y a la carencia natural del recurso, se unen los problemas de contaminación y dificultades en 
los tratamientos, lo que complica la disponibilidad de los mismos, lo que hace más necesaria la búsqueda de alternativas para garantizar el suministro. El uso cada vez más extendido de su reutilización, permite aumentar las dotaciones, circunstancia especialmente importante en la cuenca mediterránea, donde estos aportes multiplican las ventajas económicas y medioambientales. Al contribuir al equilibrio entre la oferta y la demanda suponen una solución coste-eficacia correcta, un efecto que es aún más valorado en los territorios hidrológicamente deficitarios.

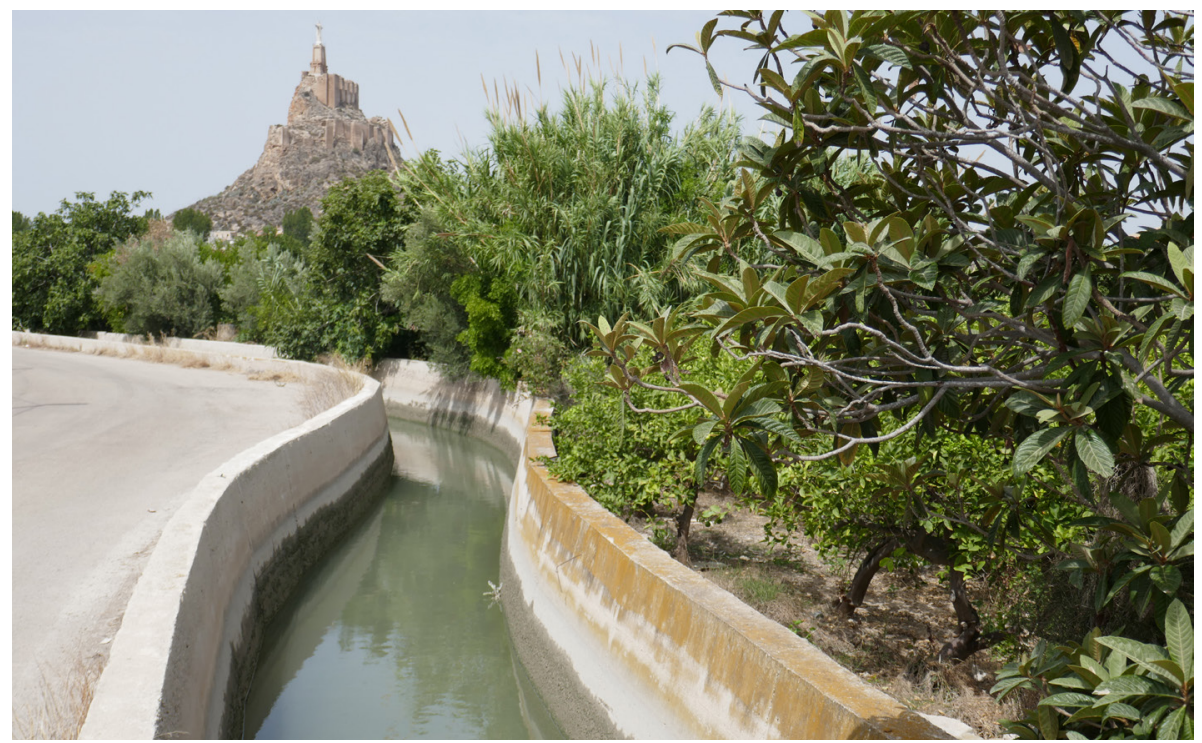

Fig. 7. El Azarbe de Monteagudo se convierte en aguas de riego en los brazales Alto y Bajo de la Cueva (Fotografía G. Canales).

Este es el caso de los espacios de regadío histórico que abastece el Segura, hecho que confiere a esta Huerta, una vez pasada la ciudad de Murcia, y sobre todo en su curso bajo, un mérito excepcional, ya que en ella son visibles los dos elementos fisonómicos más representativos de este ámbito geográfico y que constituyen un auténtico patrimonio. El primero de ellos, de más fácil identificación por su naturaleza material, es su revalidada y sólida red de riego y avenamiento, un trabado y preciso tejido hidráulico que debe recibir el calificativo de monumental. El segundo, de carácter inmaterial, obedece al rasgo distintivo que más la define y por lo que se ha sustentado este modelo agrario, el uso comunitario e intensivo del agua. Una interacción que entrańa aplicar reglas compartidas, saberes comunes, avalados por la práctica ensayo-error, y unas normas jurídicas. Todas estas relaciones hicieron posible bonificar saladares, drenar los terrenos marjalencos, eliminar el carrizal y poner la planicie aluvial en cultivo. Hay que señalar que este 
logro fue posible gracias al empleo de las aguas caballeras que circulan por el río, así como a la reutilización de las filtradas tras los riegos, es decir, las denominadas de retorno o resucitadas.

El regadío tradicional huertano, ante la controversia actual generada en torno a los conceptos de eficiencia y sostenibilidad inherentes al mismo, debe reivindicar que estos atributos los ostenta, en mayor medida, cuando dominan los métodos y técnicas agronómicas vernáculas, frente a la supuesta modernización, fundamentada en la implantación del riego por goteo, que se presenta como el paradigma de incrementar la competitividad y mejorar la gestión de los recursos. El proceso histórico de gestación de la Huerta refleja la doble dinámica que ha atravesado este espacio, por un lado, el grado de intensificación, logrado en el uso comunitario del agua, un recurso limitado y escaso del que secularmente se ha sabido sacar el máximo partido con los caudales reaprovechados; por otro, el grado de extensificación, mediante la prolongación de cauces de distribución o nuevas derivaciones que evidencian la considerable ampliación de la superficie regada, a costa de la erradicación de suelos encharcados e insalubres, devenidos a tierras fértiles de labor para implantar la agricultura. Sin olvidar, que ambos aspectos repercutieron en un extraordinario desarrollo territorial, que buscó el equilibrio entre la manipulación inevitable de los recursos naturales y sus consecuencias medioambientales, generando por consiguiente un paisaje antrópico único, al constituir un modelo cultural excepcional en su estructura y funcionamiento, que permanece vivo a pesar de las amenazas que se ciernen sobre él.

El objetivo que se persigue de la sostenibilidad es hoy ampliamente compartido por todos los agentes sociales, y exige a corto plazo, la adopción de medidas conducentes al aprovechamiento del sistema de producción vigente, procurando el menor agravio posible al medio natural en el que se inserta; mientras que a largo plazo, es preciso poner remedio a los daños ya causados y minimizar los problemas que puedan surgir en el futuro, fruto de la ruptura que supuso la nueva orientación dada al uso del suelo, que entró en competencia con otros sectores económicos. En este sentido, las medidas de desarrollo que se preconizan desde la Política Agraria Comunitaria seguirán siendo un factor significativo del cambio y el progreso del sector primario, al ofrecer a los agricultores oportunidades para mejorar sus explotaciones y, en general, el medio en el que viven. Son tres las líneas estratégicas a seguir, primera, la repercusión del cambio climático y la gestión sostenible de los recursos naturales; segunda, el mantenimiento de la superficie cultivada en toda la UE y garantizar una economía rural viva; tercera y última, asegurar la producción viable de alimentos que abastezca a una población mundial en crecimiento. 


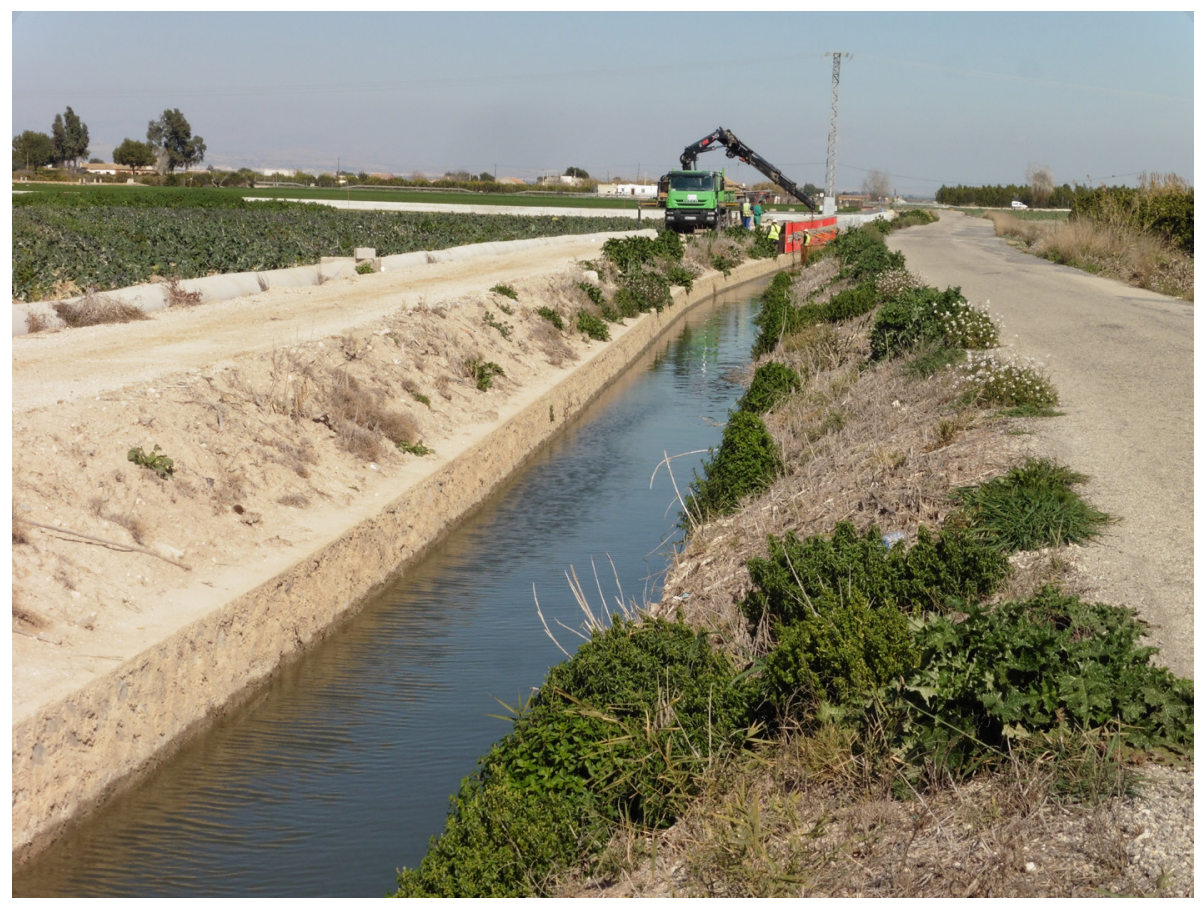

Fig. 8. Las aguas muertas del Azarbe del Término confluyen mediante el Azarbe Viejo en el Azarbe de la Reina, utilizadas en este acueducto como vivas (Fotografía G. Canales).

En este sentido, el regadío no sólo responde a las pretensiones de la Unión Europea, sino que es una actividad eficaz y rentable, pues, como explican algunos autores, se corresponde con un uso no consuntivo (Playán, 1994), en tanto que esos flujos, fruto de la percolación profunda producida por la técnica de riego a manta, han sido ya consumidos en terrenos anteriores. Por ello, el agua usada se ve sujeta a un doble efecto, el de concentración, derivado de la evapotranspiración de los cultivos, y el de meteorización, provocado por la disolución de sales presentes en el suelo o en los sustratos subyacentes (Aragüés, 1994). Ambos incrementan la salinización de estos caudales y producen la contaminación de las tierras receptoras, de ahí que la modernización, fundamentada casi exclusivamente en la implantación del goteo, no se encuentra respaldada mayoritariamente, si no viene avalada por una dotación de agua de calidad.

La propia experiencia observada en el entorno, al implantar esta técnica en la transformación del secano al regadío, ha conducido a un modelo mucho más insostenible. Esta afirmación se evidencia en dos aspectos claves, primero, en vez de conseguir una reducción del consumo de los volúmenes hídricos -fin últimoha producido una mayor demanda, al aumentar las superficies acogidas a esta nueva modalidad; segundo, no se han adquirido conocimientos para su práctica, 
y además, existe el agravante de la nula o escasa supervisión por parte de las distintas escalas de la administración (Sanchís, 2016). Los retos que debe abordar la Huerta, para erigirse como una actividad económica, competitiva y duradera -sostenible- debe exigir a los responsables de las políticas públicas sectoriales, a las que compete la actividad económica, una revisión y acuerdo sobre la verdadera eficiencia de lo que supone la modernización agraria. Ésta pasa por la recuperación de una agricultura orgánica y la accesibilidad a unos recursos hídricos óptimos, distribuidos en su justa medida, toda vez que, valorados como no consuntivos, puesto que la ingeniaría hidráulica concebida para la construcción de este paisaje permite una reutilización continua de las aguas, y por tanto, sacar el mayor provecho y rentabilidad a los escasos volúmenes asignados por el órgano de gestión de la Cuenca Hidrográfica del Segura.

\section{UNA HUERTA CADA VEZ MÁs URbaNizADa}

Los cambios socioeconómicos experimentados a partir de la segunda mitad del siglo XX hasta nuestros días, han impactado en ambas Huertas con modificaciones notables en su organización territorial, reflejadas en una alteración de los usos del suelo donde predomina la ocupación urbana. En Murcia, motivadas por el dinamismo de la ciudad central, mientras que, en la Vega Baja alicantina, ese proceso se relaciona con la actividad turística-residencial. En sendos casos, se ha asistido a un giro de mentalidad de la población asentada en el regadío histórico, fruto de la pérdida de rentabilidad de la agricultura minifundista y de la búsqueda de mejores condiciones laborales fuera del sector primario; si bien, en estos procesos, permanece el apego al lugar e incluso a las funciones tradicionales, que ahora quedan relegadas a una menor dedicación. Es de destacar, que la evolución propia de este espacio ha producido una significativa mutación paisajística y cultural que se puede concretar en tres fases cronológicas.

La primera se desarrolla hasta mediados de la década de los sesenta, hito que supone el final hegemónico de los aprovechamientos herbáceos de ciclo corto, que permitían obtener incluso cuatro cosechas cada año en una misma parcela. Hasta este momento, toda la llanura se caracterizaba por una gran homogeneidad fisonómica, tanto por los cultivos dominantes, como por los asentamientos cuya distribución espacial daba prioridad al espacio productivo, generando así un sistema de núcleos urbanos periagrícolas. El parcelario dominado por los citados rendimientos de rotación, con alternancia de cereales, hortalizas, tubérculos y plantas industriales, ha ofrecido históricamente una amplia permeabilidad visual y la percepción dinámica del trabajo agrícola. Esta estampa se transforma con la construcción de los pantanos de cabecera en la Cuenca del Segura, para paliar las temidas inundaciones, a la vez que, garantizar el suministro de caudales en la época de verano. Especial incidencia tuvieron los embalses del Cenajo y 
Camarillas, construidos en 1960, pues posibilitaron una progresiva conversión del espacio ante la seguridad del abastecimiento hídrico en los meses más secos.

La segunda, abarca los tres decenios siguientes, momento en que se inicia la plantación masiva de los cultivos arbóreos de regadío, con predominio de los cítricos. En efecto, durante esos años la producción agrícola mantiene su hegemonía en la economía local, a la vez que da el salto de unos rendimientos de subsistencia a otros de mercado, cuando el arbolado se introdujo como alternativa de plantación para romper así la horizontalidad distintiva de este llano aluvial. Poco a poco, se acorta el alcance visual con la barrera que introducen los huertos de cítricos, al generar una imagen estática, donde las copas de los árboles muestran un verde permanente, pero esconden el movimiento de las labores agrícolas propias y desconectan el paisaje vivido -el de los agricultores- y el paisaje percibido -el de las personas que transitan por él-. Todo este proceso coincide con la evolución del sistema productivo que, en líneas generales, se verá afectado por múltiples variables, como son: el éxodo rural, la mecanización de las tareas, la disminución del número de jornaleros, la aparición de cuadrillas de trabajo especializadas, la consolidación de la explotación directa de la tierra, la agricultura a tiempo parcial y los cambios en el modo de comercialización, entre otros (Canales y Ponce, 2016).

Por último, la tercera, implica la pérdida de suelo agrícola ante la expansión que adquiere el desarrollo urbanizador; este hecho se inicia más tempranamente en la capital murciana, por el crecimiento que experimenta, al encontrarse ceñida de tierras regadas va ocupando la primera corona periurbana, situación ya consolidada en los años ochenta y que continúa activa. Por el contrario, en la vega vecina, tiene mayor incidencia a partir de 1994, con la aprobación de la nueva legislación urbanística valenciana que da paso a una urbanización fragmentada de la Huerta arbolada. Es de destacar, la rapidez con la que este fenómeno se ha apropiado del territorio agrario, conduciendo a un cambio de paradigma en su gestión. En este contexto, a las ciudades rectoras se une el protagonismo, en materia de planeamiento, que adquieren las pedanías de Murcia o el resto de cabeceras municipales en la Vega Baja, pues ampliaron considerablemente sus respectivos núcleos. La consecuencia es la formación de un continuo urbano consolidado, donde las carreteras, además de garantizar las conexiones entre las principales localidades, propician en sus bordes la implantación tanto residencial como industrial. Igual sucede en la malla de caminos, vinculada a la red de riego-avenamiento, origen de los pueblos-calle; desde ambas infraestructuras de tránsito se invade el espacio huertano, al aprovechar la facilidad de accesibilidad y la planitud del terreno. 


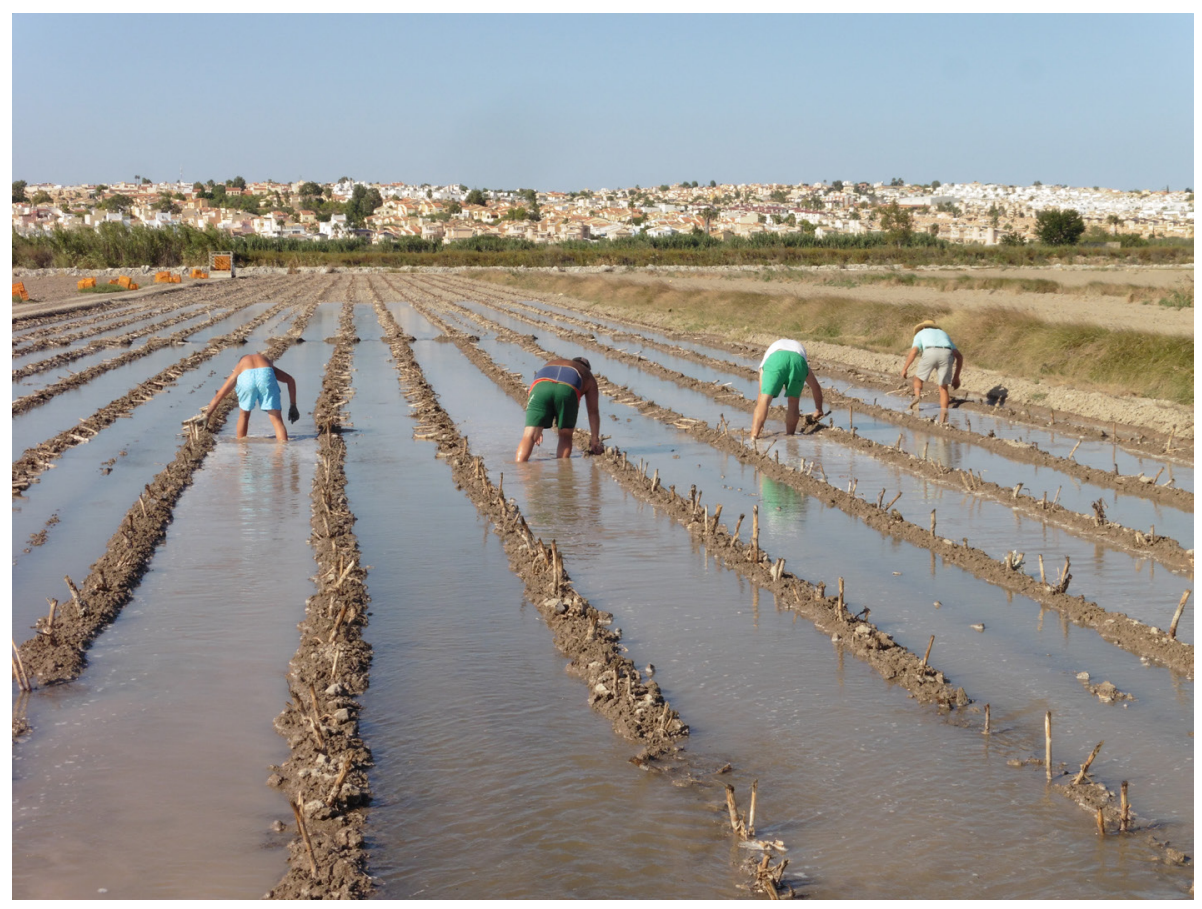

Fig. 9. Las urbanizaciones turístico-residenciales presionan el espacio cultivado próximo a la costa (Fotografía G. Canales).

La expansión urbana que experimenta Murcia en la segunda mitad del siglo $\mathrm{XX}$ es el elemento clave en la configuración de la urbe actual y llevó consigo el retroceso de la superficie cultivada. El desarrollo industrial y de las actividades terciarias son los factores que estimularon un proceso urbanizador sin precedentes, como resultado, el incremento de la oferta de trabajo atrajo a una población de origen rural que se concentró en la ciudad y área periurbana. Circunstancia que se agudiza en las últimas décadas del siglo XX, cuyo resultado ha dado lugar a la formación de una aglomeración urbana entorno al núcleo capitalino -con funciones propias de un lugar central de primer orden- al ocupar su perímetro circundante con la construcción y penetrar en el suelo agrícola de la fértil Huerta. Unas actuaciones amparadas por una legislación urbanística, desprovista de carácter innovador, que se fue refundiendo en el transcurso del tiempo, bajo el criterio de que la ampliación del tejido urbano era el único modo de ordenar el territorio, de ahí que el resultado final haya sido todo lo contrario, unas coronas periurbanas desordenadas (Andrés, 1995).

En este sentido, es de destacar que la consecuencia directa de estos planteamientos condujo a una fuerte especulación del suelo, hasta el punto que se tuvo que recurrir, para alguna de esas acciones, a la expropiación forzosa. Esta 
circunstancia impulsó un cambio decisivo en el régimen de tenencia de la tierra con la desaparición de los arrendamientos, sustituidos por la explotación directa puesto que los grandes propietarios para realizar las enajenaciones necesitan liberar de cargas sus predios y venden parte de ellos a los antiguos colonos. Así, no sólo se acentuó el minifundismo, sino que, además, unos y otros se convirtieron en verdaderos especuladores del suelo en la brusca mutación que experimentó la superficie cultivada, donde la agricultura ya no era la función dominante, ni por su peso en la población activa, ni por su participación en la producción final. Una tendencia que se agudiza cuando los terrenos de secano se incorporan al regadío, a partir de los años ochenta, con la llegada de las aguas foráneas del Tajo. En definitiva, son cuatro los principios básicos que caracterizan la aglomeración murciana: el fuerte crecimiento demográfico; la progresiva expansión del negocio inmobiliario; el incremento de las actividades no agrícolas y la continua orientación laboral de la población hacia los sectores secundario-terciario (Andrés, 1992).

Por el contrario, en la Huerta del Bajo Segura, la merma de este espacio no se vincula tanto al crecimiento de la ciudad de Orihuela, sino que está motivado por el uso turístico-residencial que ha penetrado hacia el interior desde la línea de costa, promovido por la Ley Reguladora de la Actividad Urbanistica de 1994, que rompe con las pautas de adaptación equilibradas que caracterizaban anteriormente el hábitat. Estas prácticas se concretan en dos modalidades, la planificación de urbanizaciones ex novo o la agrupación de viviendas, ambas, emplazadas en medio de los fértiles terrenos de vega. De esta manera, el patrón territorial ha evolucionado de un sistema compacto y respetuoso con el medio agrícola, a otro disgregado e invasivo con doble carácter, unifamiliar o plurifamiliar. El primero de ellos se desarrolla de forma aislada, en pequeños conjuntos vecinales (hasta cinco casas), o en complejos residenciales de mayor tamaño, tanto dispersos como contiguos al tejido urbano consolidado; sin embargo, el segundo, forma siempre parte de núcleos preexistentes. Todos ellos generan una ruptura evidente en la percepción del paisaje de Huerta, con un elevado impacto medioambiental.

El resultado ha sido la aparición de conurbaciones y la proliferación de corredores comerciales, tendencia desarrollada hasta la crisis económica de 2007, que se vio bruscamente paralizada y dejó inconclusos ambiciosos planes parciales proyectados con el atractivo de incorporar campos de golf, como aliciente para generar cientos de viviendas en su perímetro. Se trata de una pauta de actuación copiada del litoral, cuyo modelo ha servido para consolidar las promociones inmobiliarias, establecidas en cuatro bandas paralelas al frente marítimo y que quedan definidas, en función de las etapas de expansión urbana, según el estudio realizado por García y Canales (2018). Así, los autores identifican, Guardamar del Segura como la primera línea de costa; prosiguen, estableciendo como segunda franja, la ocupación de los cabezos prelitorales que ciñen la desembocadura (municipios de Rojales y San Fulgencio); para fijar como tercer sector, la zona 


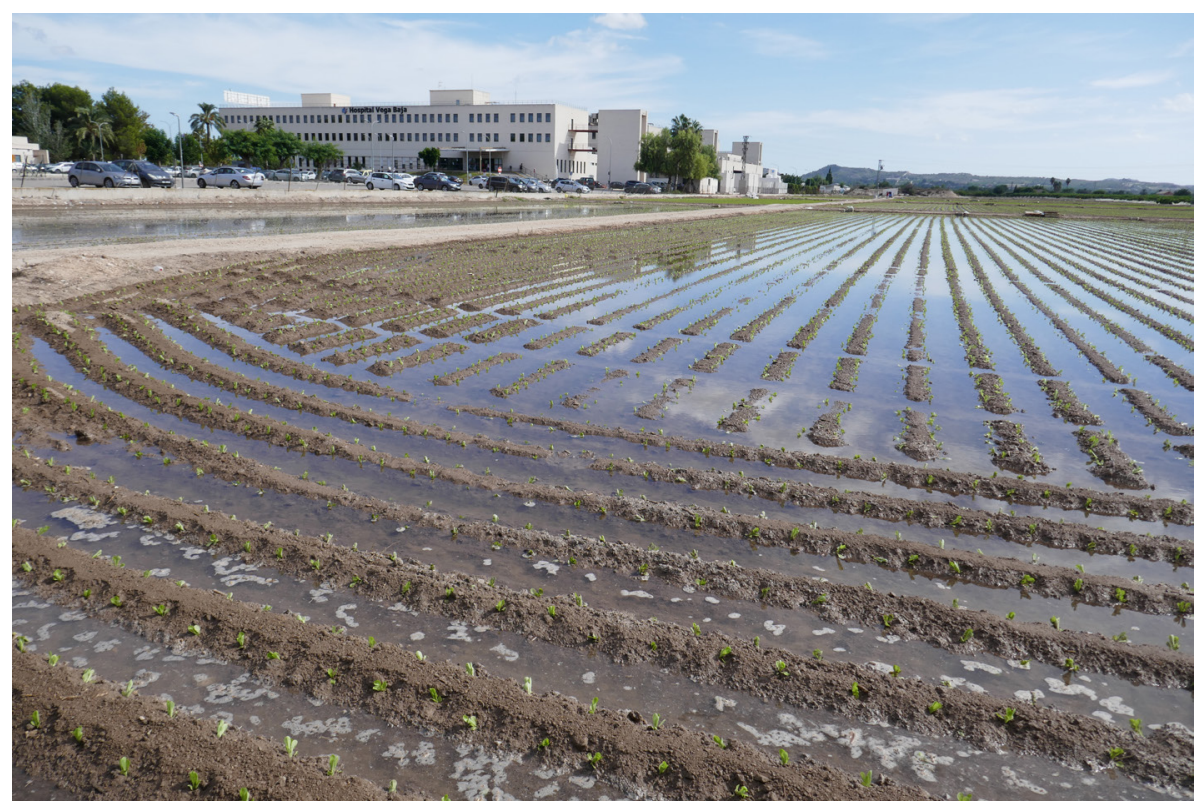

Fig. 10. La carencia de una ordenación del territorio emplazó el Hospital Comarcal de la Vega Baja en pleno llano de inundación del Segura (Fotografía G. Canales).

interior de la planicie huertana, que comprende las demarcaciones de Daya Nueva, Daya Vieja y Formentera; y, por último, superados los diez kilómetros, determinan la urbanización difusa en el término de Catral. Los cambios sustanciales experimentados en el área más oriental de la Huerta han generado un importante impacto en el enclave agrícola, de manera que las nuevas formas de urbanización artificializan y provocan una fragmentación del espacio cultivado, con la consiguiente desafección por parte de sus habitantes.

\section{Conclusiones}

Las Huertas de Murcia y Orihuela son un ejemplo representativo de los paisajes del agua, pues el río Segura se convierte en el artífice de las mismas, siendo ellas las composiciones más sublimes de él, al crear el territorio huertano, cuya localización se extiende siguiendo el mencionado curso fluvial. Este preciado bien es el modelador espacial y el causante de una auténtica cultura, que durante milenios ha mantenido el desarrollo socioeconómico de este territorio. Su potencial se sustenta en el entramado de canalizaciones, proyectadas con precisión científica, para dominar un entorno en sus orígenes marítimo y posibilitar el asentamiento de colonos. Esta condición determinó la implantación, dilatada en el tiempo, de una infraestructura hidráulica de extraordinaria magnitud por la planicie sedimentaria. Obra, constituida por una doble red, tanto de riego 
como de avenamiento, debido al manto impermeable localizado en el subsuelo, que requiere en mayor medida la existencia del drenaje, pues de lo contrario se mantendría el terreno encharcado. La escasez de recursos hídricos disponibles motiva la utilización de las filtraciones provenientes de los riegos, los denominados caudales de retorno o aguas resucitadas, circunstancia que se ha agravado después de la implantación de una agricultura química con todo el poder contaminante que arrastra.

Se trata de un paisaje de profunda intervención humana, éste ha sido el rasgo más significativo que continúa vigente, si bien, los intereses son ahora distintos, derivados éstos de la crisis de la agricultura familiar de carácter minifundista, donde la especulación inmobiliaria urbana, para uso residencial o turístico, provocaron un acelerado deterioro paisajístico dando lugar a una Huerta urbanizada. Ambas vegas han sido históricamente lugares de intenso poblamiento, pues el espacio de producción se encontraba muy próximo al mismo e incluso contiguo. El acelerado cambio económico acaecido en las últimas décadas del siglo $\mathrm{XX}$ ha supuesto una dramática ruptura de este agrosistema, al apostar por el privilegiado dinamismo del sector terciario -basado fundamentalmente en la construccióngenerador de ejes viarios rápidos que atentan contra la integridad del enclave agrario. La reacción de la sociedad frente a la falta de productividad agrícola y los ventajosos beneficios generados por la venta de solares, así como, los nuevos valores generacionales, produce una falta de apego a la tierra y a las manifestaciones culturales inherentes a ella. Sólo de esta manera, se puede comprender la rápida desaparición de los bienes, modos de vida y costumbres patrimoniales vinculados a este espacio tradicional de agricultura intensiva y el peligro de extinción de los que han conseguido perdurar hasta nuestros días.

En un intento de respuesta ante este panorama, surgen movimientos sociales en Defensa de la Huerta, no para el simple mantenimiento de un icono romántico, sino, para su protección y preservación como espacio funcional, en previsión de que la coyuntura económica favorable a otros usos pueda revertir. Estos colectivos abogan por mantener una actividad rentable durante siglos y que ha generado un paisaje cultural atractivo -fruto del devenir histórico- y cuya destrucción sería irrecuperable. La Huerta ha sido, hasta la crisis reciente, un territorio en conflicto, donde se enfrentaban los planteamientos políticos y empresariales, que apoyaban un desarrollo vinculado a la construcción, y diversas asociaciones cívico-sociales -integradas por agricultores y, mayoritariamente, por jóvenes y gentes vinculadas a la cultura- que optan por conservar sus seńas de identidad, sin que se pierda la producción agrícola, visible cada vez más a rodales entre un continuo urbano.

Un buen ejemplo de esta dualidad de intereses lo constituye la reciente tramitación ante la U.N.E.S.C.O., por parte de la Comunidad Valenciana y de la Región de Murcia, del expediente para la declaración como Patrimonio de la Humanidad de El Tribunal de las Aguas y el Consejo de Hombres Buenos; 


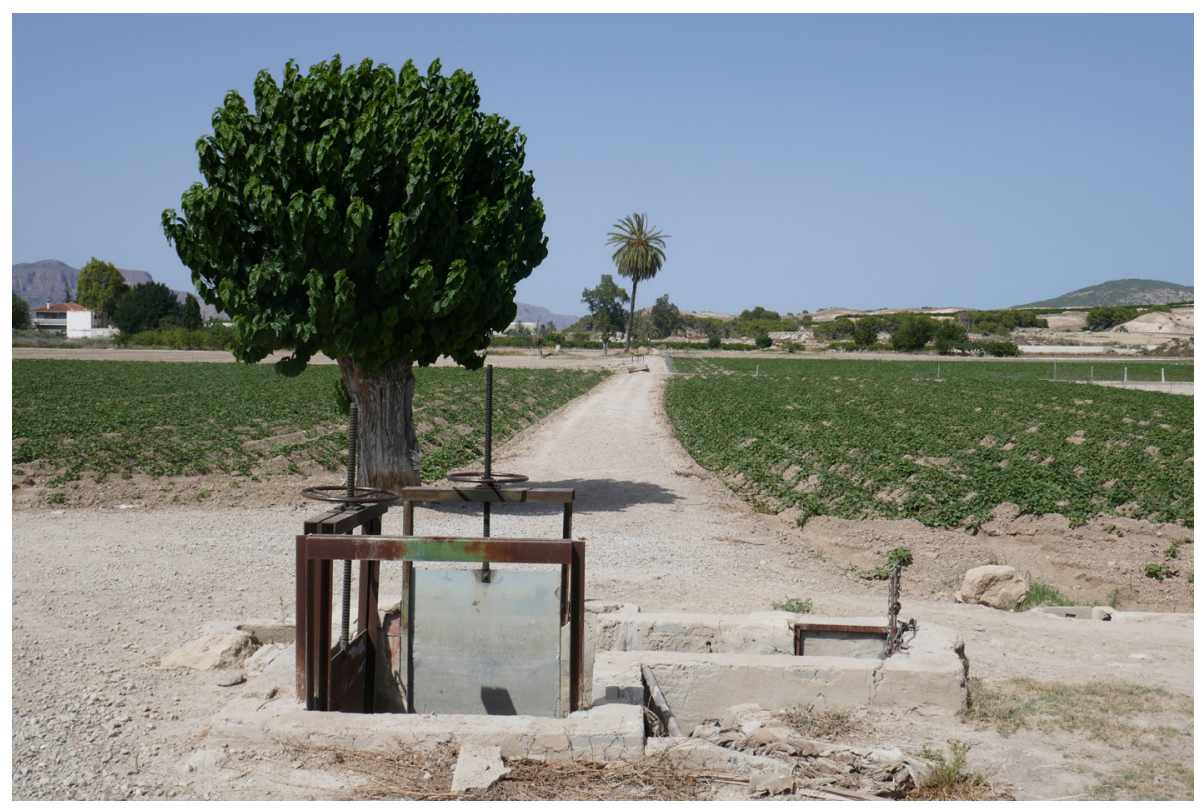

Fig. 11. Entre las diversas alteraciones que ha experimentado la Huerta se encuentra la pérdida de visibilidad de la red de riego, cuyos hitos visibles son los partidores que emergen en los nuevos viarios (Fotografía G. Canales).

instituciones que dirimen los contenciosos relacionados con el agua y su reparto en los regadíos históricos de Valencia y Murcia, respectivamente. Ambos organismos fueron incluidos en el Catálogo de Bienes Inmateriales de la Humanidad en septiembre de 2009, si bien, esta protección debería extenderse más allá de lo que es la propia organización y vincular una importante superficie agrícola para salvarla de posibles especulaciones en el futuro. Resulta sorprendente que en esta tramitación se haya dejado de lado a los Juzgados Privativos de Aguas que existen en la antigua Huerta de Orihuela y cuyas primeras ordenanzas ya quedaron plasmadas por Alfonso X el Sabio tras la conquista cristiana en el siglo XIII. De haber contado con esta salvaguarda, se habría evitado el retroceso y deterioro que ha sufrido. El mantenimiento de este legado cultural exige, por tanto, el respaldo amplio y el compromiso de toda la sociedad, insensible a esta necesidad años atrás, aunque en la situación actual la concienciación social está cobrando mayor fuerza. Por ello, es necesario incorporar el espacio subjetivo a la función pública y administrativa, y, hacer de la participación ciudadana, no sólo un estilo de gobierno, sino un instrumento insoslayable en la toma de decisiones para la ordenación y el desarrollo territorial (Ponce, 2011).

La diversidad de actividades que impulsó, especialmente el sector terciario, y el retroceso en la rentabilidad de la agricultura, favorecieron el crecimiento de 


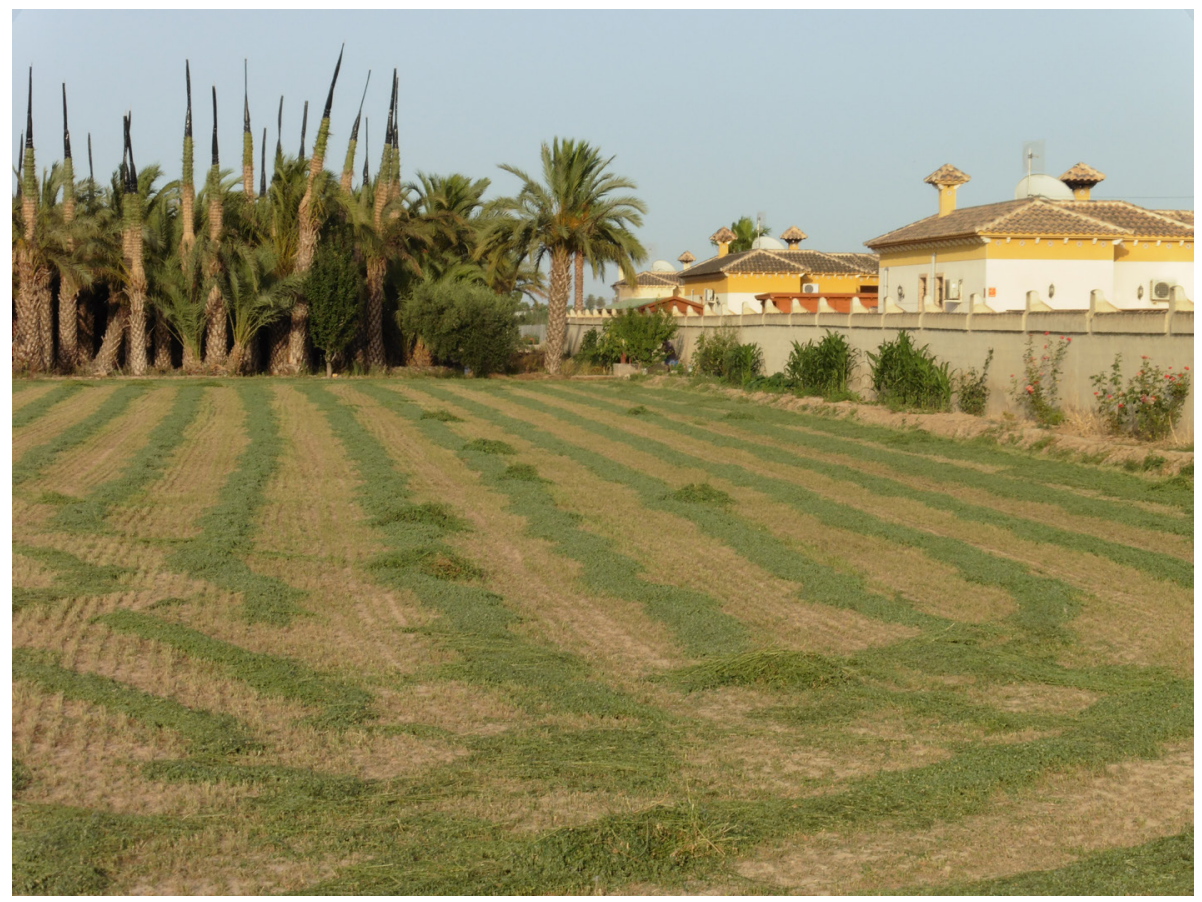

Fig. 12. El hábitat turístico-residencial rompe la unidad de producción agrícola, supone un obstáculo a la contemplación del paisaje e introduce un componente disonante en la Huerta (Fotografía G. Canales).

la economía fundamentada en el desarrollo urbanístico y la construcción, lo que se tradujo en una ocupación paulatina del llano aluvial y la aparición de nuevos usos dispersos por la vega. De esta manera, se desequilibró el sistema tradicional de cultivo, rasgo distintivo de la zona, aunque perdura el patrón geométrico y espacial que estructuró el escenario huertano sobre la red de agua, los caminos y el parcelario. Elementos, todos ellos, identificables y legibles en la actualidad, que evocan todavía las descripciones de los cronistas árabes y las interpretaciones realizadas a lo largo de los siglos por diferentes autores, estudiosos o artistas, que recogieron en sus obras la esencia de la Huerta. En la medida en que los paisajes conforman el marco de relaciones y vida de una sociedad, condicionando su bienestar, resulta relevante y trascendente comprender la dinámica de los territorios y, poder así, anticipar las tendencias de cambio, al igual que identificar en qué medida éstas modifican la idiosincrasia del lugar. Aunque los procesos descritos han transformado la mentalidad de la sociedad local y se ha diluido la identidad cultural, contradictoriamente, el imaginario colectivo reproduce un icono idealizado perteneciente más al pasado que a la realidad del siglo XXI. 
La responsabilidad de este complejo proceso se atribuye, a priori, a los actores endógenos, los propios residentes en la Huerta que acuden a las ciudades $\mathrm{y}$ a las cabeceras municipales al interesante mercado de trabajo que ofertan, sobre todo en el sector terciario, con mejores condiciones laborales y sueldos, aunque mantienen una agricultura a tiempo parcial que complementa las rentas familiares. Esta opción provoca la rururbanización y la reviste de una revolución cultural que deja su huella en el espacio, con profundas transformaciones sociodemográficas y financiero-espaciales. La fisonomía se modifica por completo al introducir funciones y patrones propios de las urbes, generándose un espacio mixto, donde alternan intersticios agropecuarios con otros claramente urbanos. La Huerta, también está ocupada por esas preferencias actuales en los modos de vida, que introducen las ventajas de vivir en un medio con mayor predomino de espacios verdes, alejado de la congestión y tráfico de los núcleos centrales, pero también, por los desorbitados precios que alcanzan las viviendas, lo que obliga a adquirirlas en el entorno periurbano; a este proceso, se suma, igualmente, el consumo de suelo para un uso turístico-residencial, más notable cuanto más próximo al litoral.

\section{BiBLIOGRAFÍA}

Agencia Europea de Medio Ambiente (1998). Medio Ambiente en Europa: El Informe Dobris. Bruselas: Oficina de Publicaciones Oficiales de las Comunidades Europeas. Madrid: Ministerio de Medio Ambiente. Ministerio de Agricultura, Pesca y Alimentación.

Andrés Sarasa, J.L. (1992). Estructura urbana de Murcia. Murcia: Real Academia Alfonso X El Sabio, 2a ed.

Andrés Sarasa, J.L. (1995). Urbanismo contemporáneo, la Región de Murcia. Murcia: Secretariado de Publicaciones Universidad.

Antrop, M. (2005). Why landscapes of the past are important for the future, Landscape and Urban Planning, 70, 21-34.

Aragüés Lafarga, R. (1994). Agricultura de regadío, calidad del agua y flujos de retorno. En Symposium Nacional "Presente y Futuro de los Regadios Españoles". Madrid: Ministerio de Fomento, Centro de Estudios y Experimentación de Obras Públicas, vol. 2 (Ponencias), 18 pp.

Azud de Alfeitamí (1793). Real Provisión de Su Magestad y Señores del Consejo, por la qual se aprueban y mandan guardar las Ordenanzas formadas para el gobierno de la Aguas del Azud de Alfeitami, término de la Villa de Almoradi, Reyno de Valencia. Almoradí: Imprenta Alonso, 1955. 
Canales Martínez, G. y Ponce Sánchez, Ma.D. (2016). Pareceres sobre la Huerta del Bajo Segura. El poder de la Identidad y la Cultura en la valoración del Paisaje. Alicante: Universidad de Alicante.

Canales Martínez, G. y Ponce Sánchez, Ma.D. (2019). Agua y sostenibilidad. La monumentalidad del edificio hidráulico de la Huerta del Bajo Segura. Alicante: Universidad de Alicante y Gobierno Provincial de Alicante, Ciclo Hídrico.

De Mancha y Rincón, R. (1836). Memoria sobre la población y los riegos de la huerta de Murcia. Murcia: Imprenta de Mariano Bellido.

Diz Ardid, E. (2017). Los primeros pobladores y la ocupación de los espacios del término actual e histórico. En Barrio Barrio, J.A. (Ed.), Orihuela. La ciudad, el río y la Huerta (pp. 16-21). Alicante: Universidad de Alicante.

Franco Sánchez, F. (2017). La estructura urbana de Orihuela en época andalusí (siglos IX-XIII). En Barrio Barrio, J.A. (Ed.), Orihuela. La ciudad, el rio y la Huerta (pp. 22-29). Alicante: Universidad de Alicante.

García Mayor, C. y Canales Martínez, G. (2018). La Vega Baja del Segura, una Huerta sitiada. La transformación del territorio. Alicante: Cátedra Arzobispo Loazes, Universidad de Alicante.

Gea Calatayud, M. De (1995). La construcción del paisaje agrario en el Bajo Segura. De los orígenes hasta la implantación de la red de riego-drenaje principal en el alfoz oriolano. Alquibla, Revista de Investigación del Bajo Segura, 1, 65-99.

Gil Olcina, A. (1976). Murcia, introducción geográfica. En Tierras de España (pp. 17-55). Madrid: Publicaciones de la Fundación Juan March, Editorial Noguer.

Gil Olcina, A. (2019). Las inundaciones en la Vega Baja del Segura. Alicante: Diputación Provincial de Alicante y Cátedra Arzobispo Loazes, Universidad de Alicante, Díptico Jornadas celebradas en el Juzgado Privativo de Aguas de Orihuela el 28 de octubre, s. p.

Jiménez Castillo, P. (2014). Murcia: de la Antigüedad al Islam. Granada: Universidad de Granada. [http://hdl.handle.net/10481/31208].

Lillo Carpio, M. (2000). La Huerta de Murcia como ejemplo de escorrentía derivada inscrita en llanura de crecida. Papeles de Geografía, 32, 61-75.

Martínez Martínez, M. (2017). La identidad del paisaje: la huerta andalusí y castellana de Murcia en el siglo XIII. HID (Historia. Instituciones. Documentos), 44, 241-267.

Molina López, E. (1972). La Cora de Tudmir según al-Udri (siglo XI). Aportaciones al estudio geográfico-descriptivo del S.E. peninsular. Cuadernos de Historia del Islam, 3, 113 pp. 
Ordenanzas y Costumbres de la Huerta de Murcia 1849-2008 (2008). Murcia: Junta de Hacendados de la Huerta de Murcia, Gráficas San Ginés.

Ordenanzas del Juzgado Privativo de Aguas de Orihuela y Pueblos de su Marco. (2017) (pp. 19-75). Orihuela: Juzgado Privativo de Aguas de Orihuela, Gráficas Minerva.

Playán Jubillar, E. (1994). Eficiencia en el aprovechamiento del agua por el regadío. Geórgica, Revista del Espacio Rural, 3, 99-128.

Roca de Togores y Alburquerque, J. (1832). Memoria sobre los riegos de la huerta de Orihuela. Valencia: Oficina de D. Benito Monfort.

Ponce Sánchez, Ma.D. (2011). Percepción de los procesos de urbanización y pérdida de los paisajes identitarios en la Vega del río Segura. En VV.AA., Urbanismo expansivo de la utopía a la realidad (pp. 555-566). XXII Congreso Geógrafos Españoles. Alicante: Asociación de Geógrafos Españoles, Universidad de Alicante,

Sanchís Ibor, C.; García Mollá, M. y Llorenç Abellá, R. (2016). Las Políticas de Implantación del riego localizado. Efectos en las entidades de riego de la Comunidad Valenciana. Boletín de la Asociación de Geógrafos Españoles, 27, 9-35.

Tent-Manclús, J.E. y Soria J.M. (2014). Formación y desecación del Sinus Ilicitanus (Sur de Alicante) en los últimos 15.000 años, Geogaceta, 55, 35-38. 